\title{
Homologous autoimplantation; an effective modality in the treatment of multiple warts; a non-randomized interventional study at a tertiary care hospital in North-Eastern India
}

\author{
Mary Zothanpuii Chhangte*, Shikha Verma, Anita Marak, Binod Kumar Thakur
} Department of Dermatology and STD, North Eastern Indira Gandhi Regional Institute of Health and Medical Sciences,
Shillong, Meghalaya, India

Received: 22 August 2021

Accepted: 01 October 2021

*Correspondence:

Dr. Mary Zothanpuii Chhangte,

E-mail: mchhangte@ymail.com

Copyright: () the author(s), publisher and licensee Medip Academy. This is an open-access article distributed under the terms of the Creative Commons Attribution Non-Commercial License, which permits unrestricted non-commercial use, distribution, and reproduction in any medium, provided the original work is properly cited.

\begin{abstract}
Background: Although there are multiple treatment options, viral warts are known for their persistence and recurrence. Surgical autoimmunization is believed to work by inducing a cell-mediated immune response to clear verrucae-inducing human papillomavirus from the body.

Methods: The study was conducted as a non-randomized interventional study at a Tertiary Care Hospital in North Eastern India. All patients above 18 years of age attending the Dermatology Clinic who were diagnosed as having multiple warts were included in the study. Autoinoculation was performed after taking patient's consent and patients were followed up monthly for 3 months. Photographs were taken at each visit to have an objective comparison, and results assessed at the end of 3 months.

Results: Out of 65 patients, 18 patients were lost to follow up and 47 patients completed the study. Complete resolution was found in 17 patients and 10 patients had partial resolution at the end of the study. The response was higher in those from the rural population compared to those from the urban areas and also in those with a short duration of the disease.

Conclusions: Autoinoculation is an effective and safe treatment modality especially in palmoplantar warts. Early intervention is required as the response was better in patients with a short duration of the disease, which was statistically significant. Further studies should be done in other clinical variants of warts to see for significant response.
\end{abstract}

Keywords: Autoinoculation, Human papilloma virus, Multiple warts, Verruca

\section{INTRODUCTION}

Warts are benign tumours that commonly involve the skin and other epithelial tissues. It is caused by different strains of Human Papilloma Virus. ${ }^{1}$ The different clinical types include verruca vulgaris or common warts, filliform verruca, verruca palmaris and plantaris, verruca plana and anogenital warts. ${ }^{2}$

Inspite of the availability of multiple treatment options, viral warts are known for their persistence and recurrence. In the treatment of multiple warts, there is no single treatment that is $100 \%$ effective and different modalities of treatment need to be combined. ${ }^{3}$ Also, destructive therapies like cautery is associated with scarring and recurrence. ${ }^{4-7}$

Surgical autoimmunization against verruca plantaris with autogenic graft of papilloma in situ was first described by Nikos Panacos in 1980, as another treatment for verruca plantaris. This implantation is believed to cause an autoimmunization process of the host to the HPV virus 
responsible for the warts. This process is believed to work by inducing a cell-mediated immune response to clear verrucae-inducing human papillomavirus from the body. Once the autoimmune reaction is complete, the verrucae usually regress in a period of 2 to 6 weeks. ${ }^{8}$

Although many studies have been done in different parts of the world on autoinoculation, none have been in done in this part of the country, therefore a need for this study.

\section{Objectives of the study}

The objective of our study was to see the efficacy of homologous autoimplantation in the treatment of multiple warts.

\section{METHODS}

The study was conducted as a non -randomized interventional study at a Tertiary Care Hospital in North Eastern India for a period of 1 year. Institutional ethical clearance was obtained before the beginning of the study with Ethics approval. All patients above 18 years of age attending the Dermatology Out patient Department who were diagnosed as having multiple warts were included in the study. Patients excluded from the study were Immunosuppressed patients, patients with history of intake of immunomodulatory or immunosuppressive drugs, pregnant and lactating mothers, patients with advanced disease of vital organs, patients already taking treatment for the disease, patients with mucosal and genital warts and patients below 18 years of age.

All patients with multiple warts of more than 1 in number, of age above 18 years and both sexes were randomly selected and included in the study after taking their consent. In each case a detailed history was taken, and a thorough general physical, cutaneous and systemic examination was carried out according to pre-structured proforma. Appropriate investigations including viral markers such as tests for Human Immunodeficiency Virus(HIV), Hepatitis C and Hepatitis B were done. Clinical photographs were taken at the beginning of the study and subsequently at every visit until the end of the study to compare the changes seen after doing the procedure. Patients were followed up after 1 month until the end of 3 months.

\section{Procedure for doing the autoinoculation}

A well-developed wart was chosen as a donor and under strict aseptic precautions and local anaesthesia, a full depth wart tissue removed with the help of a blade and forceps. With the help of a 20 Gauge needle, a small subcutaneous pocket was made on the flexor aspect of the nondominant forearm around 2 inches below the antecubital crease. With the same needle the harvested tissue was inserted into the subcutaneous pocket after crushing it with forceps at the recipient site using to and fro movements. The area was dressed and covered with adhesive plaster. Patients were followed up monthly for 3 months and photographic evidence was taken at each visit to have an objective comparison.

Objective comparisons were made at each visit to compare the decrease in number and size of the warts. Results were evaluated as no resolution, partial resolution and complete resolution where no resolution meant no change at all in the size and number of warts, partial resolution meant some decrease in the size and number of warts and complete resolution meant complete reduction of the warts to no warts at previous sites at the end of the study. Adverse effects were asked to be noted by the patient themselves and were asked to report if they noticed anything by telephone.

\section{Statistical analysis}

The efficacy of therapy was calculated in terms of percentage of patients showing response. Pearson chisquare test was used to check for statistically significant results between the resolution of lesions with respect to the age, gender, duration, residence, type of warts and other variables. $\mathrm{P}$ value equal to or $<0.05$ was taken as significant.

\section{RESULTS}

The study was done on 65 patients out of which 43 $(66.2 \%)$ were males and $22(33.8 \%)$ were females. The male:female ratio was $2: 1$. Out of 65 patients, 18 patients (27.6\%) were lost to follow up and 47 patients $(72.3 \%)$ completed the study. Results were evaluated from the 47 patients.

Clinic-demographic profile of patients has been given in Table 1.

The mean age was 27 years. Majority of the study participants were in the age groups of $18-38$ (92.3\%).

Out of 65,49 patients $(75.4 \%)$ were from the urban areas and 16 patients $(24.6 \%)$ were from the rural areas.

29 patients (44.6\%) had history of more than 12 months of warts, 21 patients $(32.3 \%)$ had a duration of less than 6 months of warts and the rest 15 patients (23.1\%) had warts for a duration of 6-12 months.

Majority of the patients (38) were students, 9 were private employees, 6 were housewives, 4 were manual labourers, 3 were army personnels, 2 were government servants, 2 more were hair dressers and 1 was a housemaid.

Majority of the patients (63.1\%) had Verruca vulgaris (common warts), 7 patients $(10.8 \%)$ had palmar warts, 4 patients $(6 \%)$ had plane warts, 2 patients $(3.1 \%)$ had plantar warts, 3 patients $(1 \%)$ had digital warts and 8 
patients $(12.3 \%)$ had combination of different types of warts.

Table 1: Clinicodemographic profile of patients.

\begin{tabular}{|c|c|c|}
\hline Parameters & $\begin{array}{l}\text { Number } \\
\text { (percentage) }\end{array}$ & $\begin{array}{l}\mathbf{P} \\
\text { value }\end{array}$ \\
\hline \multicolumn{3}{|l|}{ Age (years) } \\
\hline $18-28$ & $43(66.1)$ & \\
\hline $29-38$ & $17(26.1)$ & 0.060 \\
\hline $39-48$ & $4(6.1)$ & \\
\hline $49-58$ & 0 & \\
\hline $59-68$ & $1(1.5)$ & \\
\hline Mean age (years) & 27 & \\
\hline Sex (Male:female ratio) & $2: 1$ & 0.436 \\
\hline \multicolumn{3}{|l|}{ Residence } \\
\hline Urban & $49(75.3)$ & 0.033 \\
\hline Rural & $16(24.6)$ & \\
\hline \multicolumn{3}{|l|}{ Occupation } \\
\hline Student & $38(58.4)$ & \\
\hline Private employees & $9(13.8)$ & \\
\hline Housewife & $6(9.2)$ & \\
\hline Manual labourers & $4(6.1)$ & 0.926 \\
\hline Army personnel & $3(4.6)$ & \\
\hline Hair dresser & $2(3.0)$ & \\
\hline Govt employee & $2(3.0)$ & \\
\hline Housemaid & $1(1.5)$ & \\
\hline \multicolumn{3}{|l|}{ Duration of warts } \\
\hline Less than 6 months & $21(32.3)$ & \\
\hline 6-12 months & $15(23.0)$ & 0.052 \\
\hline More than 12 months & $29(44.6)$ & \\
\hline \multicolumn{3}{|l|}{ Type of warts } \\
\hline Verruca vulgaris & $41(63.0)$ & \\
\hline Palmar warts & $7(10.7)$ & 0.293 \\
\hline Plane warts & $4(6.15)$ & \\
\hline Plantar warts & $2(3.07)$ & \\
\hline Digital warts & $3(4.61)$ & \\
\hline $\begin{array}{l}\text { Combination of different } \\
\text { types of warts }\end{array}$ & $8(12.3)$ & \\
\hline
\end{tabular}

At the end of 1 month,7 (14.8\%) patients had complete resolution of the lesions, 14 (29.7\%)patients had partial resolution and $26(55.3 \%)$ patients did not have any resolution of the lesions.

At the end of 2 months, another 5 patients had complete resolution of the lesions, and another 1 had partial resolution.

At the end of the study ie after 3 months, 17 patients $(36.1 \%)$ had complete resolution of the lesions, 10 patients $(21.2 \%)$ had partial resolution and 20 patients $(42.5 \%)$ did not have any resolution of the lesions. (Figures 1-3)

The time taken for resolution for majority of the patients $(81.4 \%)$ was $1-2$ months, 3 patients (11.1\%) had resolution in 3 months and 2 patients (7.4\%) had resolution in less than 1 month. Patients responded as early as 3 weeks for resolution.

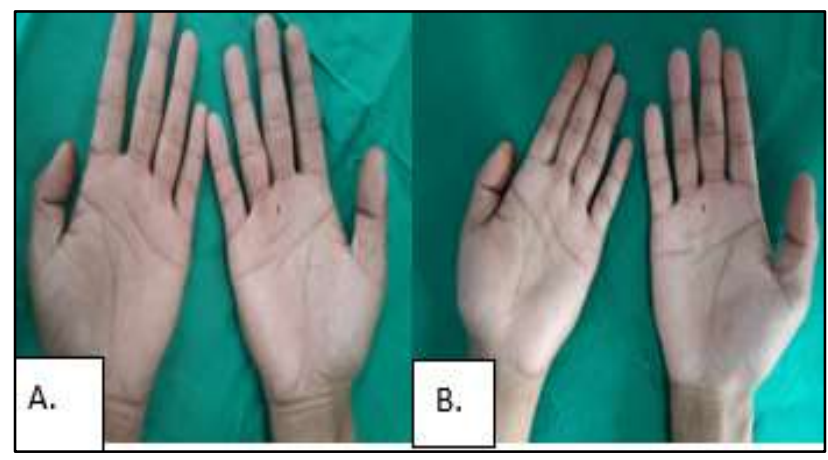

Figure 1: (A) Before autoinoculation. (B) Partial resolution of lesions after autoinoculation.

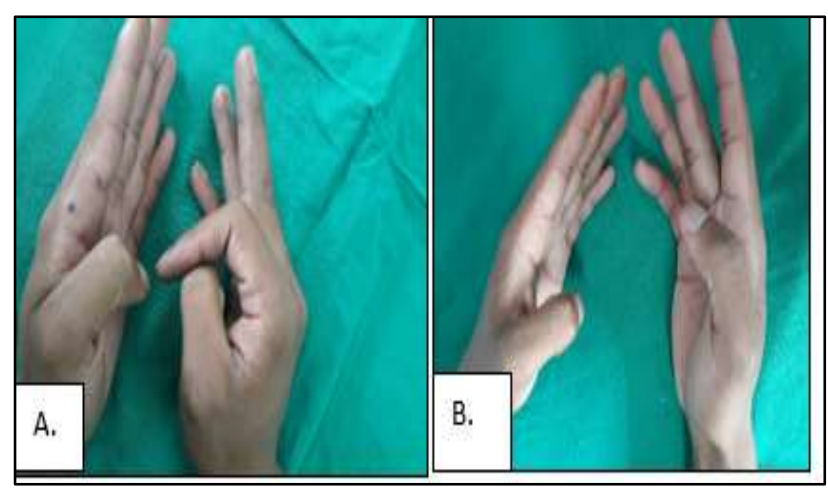

Figure 2: (A) Before autoinoculation. (B) Complete resolution of lesions after autoinoculation.

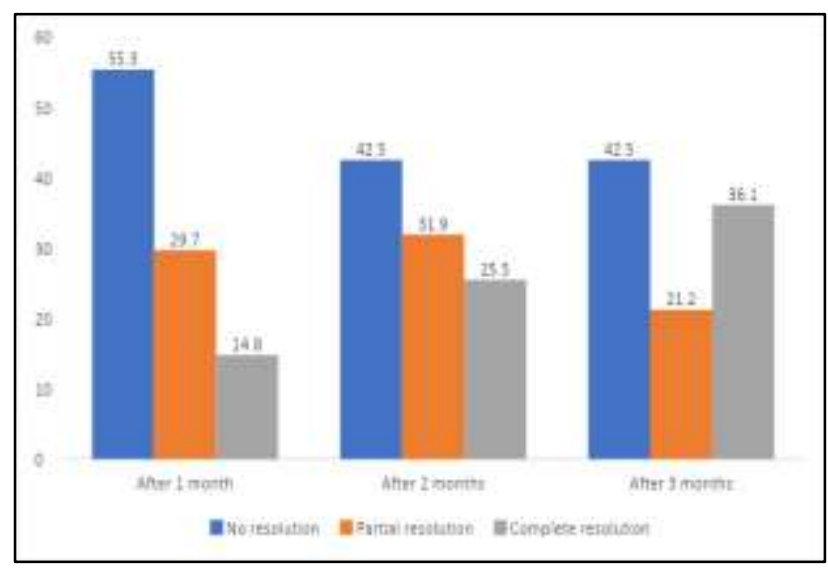

Figure 3: Pattern of resolution of lesions after inoculation.

Pearson chi-square tests were done for associations between gender, duration of the lesions, age grouping of patients, types of warts, occupation, urban and rural residents and the resolution of lesions. (Table 1)

We found a $100 \%$ response to autoinoculation therapy in plantar warts and $66.7 \%$ response in palmar warts and a 
$28.1 \%$ response in patients with Verruca vulgaris. These findings were, however, not statistically significant.

It was also found that resolution was higher in those with a short history of the disease than those who had a long duration of more than a year which was statistically significant.

The complete resolution was higher among the rural residents comparing to the urban residents with a $\mathrm{p}$ value of 0.03 which was statistically significant.

Our study found no significant correlation between age, gender and occupation with resolution of lesions.

\section{DISCUSSION}

Viral warts are papillomas caused by the human papilloma virus (HPV) and can grow anywhere on the body, commonly on the hands and feet. Although some warts regress spontaneously, most require treatment. Management is difficult, primarily due to recalcitrance to standard therapy and high recurrence rates. The potential for spread to contiguous sites and to contacts along with disfigurement and psychosocial effects result in considerable morbidity and a constant demand for a cure. Currently available options including cryosurgery, laser, electrosurgery, curettage, and topical keratolytics are generally painful and limited by recurrences. ${ }^{9}$ The absence, or reduction, of a cellular response may explain why verrucae treatments are not uniformly successful and treatment can be difficult even in immune-competent individuals. $^{10}$

The ideal aims of the treatment of warts should be to remove the wart without recurrence, avoid aggressive (potentially scarring) procedures, and to assist the immune system in dealing more effectively with the virus and inducing life-long immunity to human papillomaviruses. ${ }^{11}$

Homologous autoimplantation is a simple technique, which helps in inducing a good cell-mediated immune response, essential for the clearance of warts. This therapy was shown to be associated with the production of Th1 cytokines. Th1 cytokines TNF $\alpha$ and IL-1 downregulate the transcription of HPV genes whereas INF $\gamma$ and IL-2 stimulate cytotoxic T cells and natural killer cells to eradicate HPV infected cells. ${ }^{9}$

In our study, $36.1 \%$ of the patients showed complete resolution at the end of 3 months. Complete clearance has been reported as much as $20-74.1 \%$ in various studies on autoinoculation. ${ }^{13} 21.1 \%$ of the patients had partial resolution at the end of 3 months. Similar findings were seen in a study done by Srivastava et al where $22.64 \%$ had partial resolution. ${ }^{12} \mathrm{We}$ found improvement in patients as early as 3 weeks which has also been seen in other studies. ${ }^{11}$
The response in the rural population was better comparing to the urban population which was statistically significant $(\mathrm{p}<0.05)$. We were not able to find similar results in other studies. This result could be due to better immunity to the virus in the rural population due to more exposure comparing to the urban population.

The response was also higher in those with a short history of the disease ( $<6$ months) compared to those with a duration longer than 6 months $(56.3 \%$ had complete resolution comparing to $27.3 \%$ complete resolution in those with lesions of more than 12 months duration) which was also statistically significant. These findings were similar to a study done by Faleiro et al where there was a decreasing response to autoinoculation therapy with longer duration of warts. ${ }^{13}$

This is contrast to a study done by Lal NR et al where it was found that the patients whose warts cleared completely had had them for a longer duration than those with partial improvement. ${ }^{9}$

Malison et al reported that in all patients with condylomas accuminatum for up to 1 year, the cure rate with autogenous vaccine was $86 \%$ compared with $0 \%$ for those with disease more than a year. ${ }^{14}$

We found a $100 \%$ response to autoinoculation therapy in plantar warts and $66.7 \%$ response in palmar warts. These findings are similar to other studies done by Shivkumar et al and Faleiro et al. ${ }^{11,13}$ Our findings were however not statistically significant.

An immunofluorescence study by Shirodaria and Mathews showed that warts from sole, heel and toe had a much higher incidence of stainable virus antigen. This could account for the better response of palmoplantar warts seen in our study. ${ }^{15}$

There was $28.1 \%$ response in patients with Verruca vulgaris. Cormia et al reported complete cure in only $20 \%$ of their cases using auto lysate therapy for verruca vulgaris. ${ }^{16}$ Faleiro et al also found that $28.6 \%$ of patients with verruca vulgaris showed complete clearance. ${ }^{13}$ Ghosh and Maplestone reported that none of the patients with verruca vulgaris showed response to auto lysate. ${ }^{17}$ However, Shivkumar et al have reported $70 \%$ clearance for verruca vulgaris which contrasts to our study. 111 patient out of 2 with plane warts responded to our therapy whereas in the study by Faleiro et al, no patients out of the 2 with plane warts responded to therapy. Ghosh and Maplestone reported cure in 9 of 12 patients with plane warts and significant improvement in those who were not cured. ${ }^{17}$ These findings may be different due to small number of patients with plane warts in our study.

There was no report of any side effects in our study similar to the study done by Srivastava et al. ${ }^{12}$ Only 2 patients reported pain at the site of inoculation which lasted for a maximum of one day. Other side effects 
which has been reported in several other studies such as post inflammatory hyperpigmentation, nodule at inoculation site, local and generalised itching were not seen in our study.

\section{Limitations}

The limitations of our study were the small sample size and the high percentage of patients lost to follow-up. Also, other types of wart such as filiform warts and periungual warts were not found in our study from which we could not assess the results.

We could not determine the HPV type to account for type specific differences in the treatment outcomes and levels of relevant Th1 cytokines were not checked to ascertain their role.

\section{CONCLUSION}

Autoinoculation is an effective and safe treatment modality especially in palmoplantar warts. Early intervention is required as the response was better in patients with a short duration of the disease, which was statistically significant. Also, further studies should be done in other clinical variants of warts to see for significant response.

Funding: No funding sources

Conflict of interest: None declared

Ethical approval: The study was approved by the institutional ethics committee

\section{REFERENCES}

1. Drake LA, Ceilley RI, Cornelison RL, Dobes WL, Dorner W, Goltz RW, et al. Guidelines of care for warts: Human papilloma viruses. J Am Acad Dermatol. 1995;32:98-103.

2. Plasencia JM. Cutaneous warts: Diagnosis and treatment. Prim Care. 2000;27:423-34.

3. Sterling JC, Handfield-Jones S, Hudson PM. Guidelines for management of cutaneous warts. Br J Dermatol. 2001;144:4-11.

4. Vickers CF. Treatment of plantar warts in children. Br Med J. 1961;5254:743-5.

5. Pringle WM, Helms DC. Treatment of plantar warts by blunt dissection. Arch Dermatol. 1973;108:79-82.
6. Baruch K. Blunt dissection for the treatment of plantar verrucae. Cutis. 1990;46:145-7.

7. Matsumoto $\mathrm{Y}$, Adachi A, Banno S, Hayashi Y, Ogiyama Y, Ohashi M. Prominent hyperkeratotic plantar and palmar warts. Cutis. 1999;63:91-4.

8. Harton FM. Surgical Autoimmunization Against Verruca: Approach and Expectations. In: The Proceedings of the Annual Meeting of the Podiatry Institute UPDATE 2001. Decatur: The Podiatry Institute Inc. 2001;59-61.

9. Lal NR, Sil A, Gayen T, Bandyopadhyay D, Das NK. Safety and effectiveness of autoinoculation therapy in cutaneous warts: A double - blind, randomized, placebo - controlled study. Indian J Dermatol Venereol Leprol. 2014;80:515-20.

10. Longhurst B, Bristow I. The Treatment of Verrucae Pedis Using Falknor's Needling Method: A Review of 46 Cases. J Clin Med. 2013;2:13-21.

11. Shivakumar V, Okade R, Rajkumar V. Autoimplantation therapy for multiple warts. Indian J Dermatol Venereol Leprol. 2009;75:593-5.

12. Srivastava PK, Bajaj AK. Autowart Injection Therapy For Recalcitrant Warts. Indian J Dermatol 2010;55(4):367-9.

13. Faleiro KN, Shukla P. Role of autoinoculation in the management of cutaneous warts: a comparison study with $100 \%$ tricholoroacetic acid application Int J Res Dermatol. 2020;6(4):537-43.

14. Malison MD, Morris R, Jones LW. Autogenous vaccine therapy for condyloma acuminata: a doubleblind controlled study. $\mathrm{Br} \mathrm{J}$ Vener Dis. 1982;58:62-5.

15. Shirodaria PV, Matthews RS. An immunofluorescence study of warts. Clin Exp Immunol 1975;21(2):329-38.

16. Cormia FE. Auto lysate therapy for verruca vulgaris. Arch Dermatol. 1934;30:44-8.

17. Ghosh LM, Maplestone PA. Warts and their and their treatment. Indian Med Gazette. 1935:441-4.

Cite this article as: Chhangte MZ, Verma S, Marak A, Thakur BK. Homologous autoimplantation; an effective modality in the treatment of multiple warts; a non-randomized interventional study at a tertiary care hospital in North-Eastern India. Int J Res Dermatol 2021;7:835-9. 